\title{
Value of Contrast-Enhanced Ultrasonography in the Differential Diagnosis of Enlarged Lymph Nodes: a Meta-Analysis of Diagnostic Accuracy Studies
}

\author{
Ya Jin ${ }^{1}$, Yu-Shuang He', Ming-Ming Zhang ${ }^{2}$, Shyam Sundar Parajuly ${ }^{3}$, Shuang \\ Chen ${ }^{1}$, Hai-Na Zhao', Yu-Lan Peng ${ }^{1 *}$
}

\begin{abstract}
Objective: To evaluate the diagnostic accuracy of contrast-enhanced ultrasonography (CEUS) in differentiating between benign and malignant enlarged lymph nodes using meta-analysis. Materials and Methods: Pubmed, Embase, SCI and Cochrane databases were searched for studies (up to September 1, 2014) reporting the diagnostic performance of CEUS in discriminating between benign and malignant lymph nodes. Inclusion criteria were: prospective study; histopathology as the reference standard; and sufficient data to construct $2 \times 2$ contingency tables. Methodological quality was assessed using Quality Assessment of Diagnostic Accuracy Studies-2 (QUADAS-2). Patient clinical characteristics, sensitivity and specificity were extracted. The summary receiver operating characteristic curve was used to examine the accuracy of CEUS. A meta-analysis was performed to evaluate the clinical utility in identification of benign and malignant lymph nodes. Sensitivity analysis was performed after omitting outliers identified in a bivariate boxplot and publication bias was assessed with Egger testing. Results: The pooled sensitivity, specificity and AUROC were 0.92 (95\% CI, 0.85-0.96), 0.91 (95\% CI, 0.82-0.95) and 0.97 (95\% CI, 0.95-0.98), respectively. After omitting 3 outlier studies, heterogeneity decreased. Sensitivity analysis demonstrated no disproportionate influences of individual studies. Publication bias was not significant. Conclusions: CEUS is a promising diagnostic modality in differentiating between benign and malignant lymph nodes and can potentially reduce unnecessary fine-needle aspiration biopsies of benign nodes.
\end{abstract}

Keywords: Contrast-enhanced ultrasonography - differential diagnosis - lymph nodes - meta-analysis

Asian Pac J Cancer Prev, 16 (6), 2361-2368

\section{Introduction}

Lymph node status is one of the major predictors of prognosis in patients with cancer (Innace et al., 2010;Deng et al., 2014; Fayaz et al., 2014; Gasparri et al., 2014; Kawada et al., 2014). Furthermore, correctly diagnosing the enlarged lymph nodes in patients with or without primary tumors is essential to allow selection of an appropriate treatment strategy (Esen., 2010). A large number of modalities may be used to characterize lymph nodes, such as computed tomography, magnetic resonance imaging and gray scale ultrasound; these depend mainly on morphological characteristics for the identification of enlarged lymph nodes (Schröder et al., 2002; Riegger et al., 2012). Gray scale ultrasound combined with color Doppler ultrasonography can be applied to estimate the shape (L/T ratio), margins, internal structure and vascularization of lymph nodes (Ahuja et al., 2002; Stramare et al., 2004). Alternative diagnostic modalities include ultrasonography-guided fine needle aspiration biopsy (US-FNAB). However, each of these various methods has its own limitations in the clinical diagnosis of lymph nodes, meriting the development of improved techniques. How to improve the diagnostic accuracy of enlarged lymph nodes and reduce unnecessary puncture of benign lymph nodes remains a challenge.

Recent advances in ultrasound technology, including commercially available ultrasonographic contrast agents (Levovist and SonoVue), contrast-specific ultrasonographic modes, and quantitative software (Qontraxt (Rubaltelli et al., 2007) and TIC analysis (Steppan et al., 2010)), have improved the accuracy of ultrasonography in the diagnosis of lymphadenopathy. This has particularly been the case for contrast-enhanced ultrasonography-guided fine needle aspiration cytology, which can improve the puncture success rate (Sun et al., 2012; Karina et al., 2013).

Nowadays, more and more studies are focusing on the use of contrast-enhanced ultrasonography (CEUS) in the differential diagnosis of benign and malignant lymph

${ }^{1}$ Department of Ultrasound in West China Hospital, ${ }^{2}$ The Center of Evidence-Based Medicine in West China Hospital, University of Sichuan, Chengdu, China, ${ }^{3}$ Department of Ultrasound, Paropakar Maternity and Children Hospital, Thapathali Kathmandu, Nepal *For correspondence: yulanpeng_scu@163.com. 
nodes (including cervical, axillary, inguinal, mediastinal and abdominal lymph nodes) and our meta-analysis provides summaries of the results of relevant studies, estimates of the average diagnostic accuracy of CEUS, the uncertainty of this average, and the variability of the study findings around the estimates.

\section{Materials and Methods}

The methodology used in this meta-analysis based on the Cochrane Handbook for Systematic Reviews of Diagnostic Test Accuracy, version 1.0 (Deeks et al., 2010).

\section{Data sources and search strategies}

We carried out a systematic literature search of Pubmed, Embase, Cochrane Library Central and SCI databases, with the last search undertaken on September 1,2014. The search terms used were: "Contrast media OR Contrast-enhanced OR Microbubble", "Ultrasonography OR Ultrasound" and "Lymph nodes". These keywords were identified in the medical subject heading, title or abstract. To identify additional relevant studies, the literature search was also performed manually.

\section{Selection of studies}

All titles and abstracts of the retrieved studies were screened independently by two reviewers. Duplicates, reviews, letters, comments, case reports, and articles reporting other diseases, other diagnostic techniques or other types of result were excluded. The corresponding author was contacted by email with a request for the full text when this could not be obtained online; if the full text or original data was not provided, the study was excluded from our analysis. The remaining studies were considered potentially eligible for inclusion, and their full text was retrieved.

\section{Inclusion and exclusion criteria}

All potentially eligible articles were assessed independently by two reviewers, using predefined inclusion and exclusion criteria. Discrepancies were resolved by consensus. If no consensus could be reached, a third reviewer was consulted.

The inclusion criteria were as follows: (a) original full paper publication; (b) human study; (c) evaluation of CEUS for the differentiation of benign and malignant lymph nodes; (d) inclusion of at least 20 lesions; (e) published in English; (f) included an accepted reference method, using specimens obtained from surgery or lymph node biopsy; $(\mathrm{g})$ reported data that allowed construction of $2 \times 2$ contingency tables and calculation of the true-positive (TP), false-positive (FP), true-negative (TN) and falsenegative (FN) rates for the use of CEUS for the diagnosis of benign and malignant lymph nodes.

The exclusion criteria were as follows: (a) no evaluation of the value of CEUS for the differential diagnosis of benign and malignant lymph nodes; (b) no relevant data on the sensitivity and specificity, or the number of TNs, TPs, FNs and FPs; (c) inclusion of less than 20 lesions; (d) review article (including meta- analyses), corresponding letter or editorial not reporting original data; (e) published in abstract form only; (f) published more than once.

\section{Data extraction}

For each study, the following information was extracted: (a) author, publication year, the type and dose of contrast agent, the type of scanners, imaging modality; (b) participant characteristics (age, sex, the number of patients and lesions and the number of lesions histologically proven to be malignant); (c) statistics for the meta-analysis: TP, FP, TN, FN, sensitivity and specificity.

\section{Quality assessment}

Methodological quality was assessed according to the revised tool for Quality Assessment of Diagnostic Accuracy Studies (QUADAS-2) (Smidt et al., 2008; Deeks et al., 2010; Whiting et al., 2011). The full QUADAS-2 tool consists of four domains: patient selection, index test, reference standard, and flow and timing. Each domain was assessed in terms of the risk of bias according to the signaling questions, and the first three domains were judged in terms of concerns regarding applicability. Each question was scored "yes" if reported, "no" if not reported, or "unclear" if there was inadequate information in the article to make a judgment.

\section{Data synthesis and statistical analysis}

To assess data inhomogeneity, a random-effects model was applied to control for differences in the reported data (e.g., patient characteristics and methods used). This represents a classic, non-iterative method to account for inter-study heterogeneity. $\chi^{2}$ and $\mathrm{I}^{2}$ statistics were computed. $\mathrm{I}^{2}$ values were interpreted according to the proposal of Higgins and Thompson (Higgins et al., 2002), with heterogeneity determined as either low $\left(\mathrm{I}^{2} \leq 25 \%\right)$, medium $\left(25 \%<\mathrm{I}^{2} \leq 50 \%\right)$ or high $\left(50 \%<\mathrm{I}^{2} \leq 75 \%\right)$. Factors influencing diagnostic accuracy were assessed by means of formal meta-regression analysis (Lijmer et al., 2002). The parameters listed in the Data Extraction and Quality Assessment sections (see above) were used as covariates. $p<0.05$ was considered to indicate a significant difference.

Summary sensitivities, specificities and the summary receiver operating characteristic curve with corresponding 95\% confidence intervals (CIs) were used to examine the accuracy of CEUS in the differential diagnosis of enlarged lymph nodes. Data synthesis was performed within the bivariate mixed-effects binary regression modeling framework (Reitsma et al., 2005). It is possible that the accuracy of the following clinical subgroups could differ, and therefore act as potential source of heterogeneity: (1) with a primary tumor versus without; (2) imaging modality: low MI with SonoVue. We evaluated subgroups according to quality assessment and data extraction.

In addition, a bivariate box plot was used to assess the distributional properties of sensitivity versus specificity and for identifying possible outliers. After omitting these outliers and according to the results of the subgroups analysis, sensitivity analysis was performed and the change in heterogeneity was observed. The Deeks' funnel plot asymmetry test was also used to investigate whether 
all the studies were from a single population, and to search for publication bias (Deeks et al., 2005).

The QUADAS figure was drawn using Revman 5.0 (Cochrane Collaboration). All statistical analyses were performed using the MIDAS and METANDI modules in Stata 12.0 (Stata Corp, Texas, USA).

\section{Results}

\section{Search results and data extraction}

A total of 442 articles were identified, and duplicate studies ( $\mathrm{n}=57)$ were excluded using EndNote software (Thomson Reuters, New York, USA). After scanning the titles and abstracts, studies that were considered irrelevant to our analysis were excluded $(n=326)$, leaving 59 potentially eligible articles. Of these 59 studies, 16 fulfilled the inclusion criteria (Moritz et al.,2000; Schmid-Wendtner et al., 2002; Rubaltelli et al., 2004; Kanamori et al., 2006; Rubaltelli et al., 2007; Hocke et al., 2008; Wang et al., 2009;De Giorgi et al., 2010; Yu et al., 2010;Podkrajsek et al., 2011; Rubaltell et al., 2011; Zheng et al., 2011; Xue et al., 2011; Slaisova et al., 2013; Poanta et al., 2014; Rubaltelli et al., 2014.). A flow chart for the study selection procedure is shown in Figure 1.

The main characteristics of the included studies were summarized in Table 1. We evaluated a total of 1495

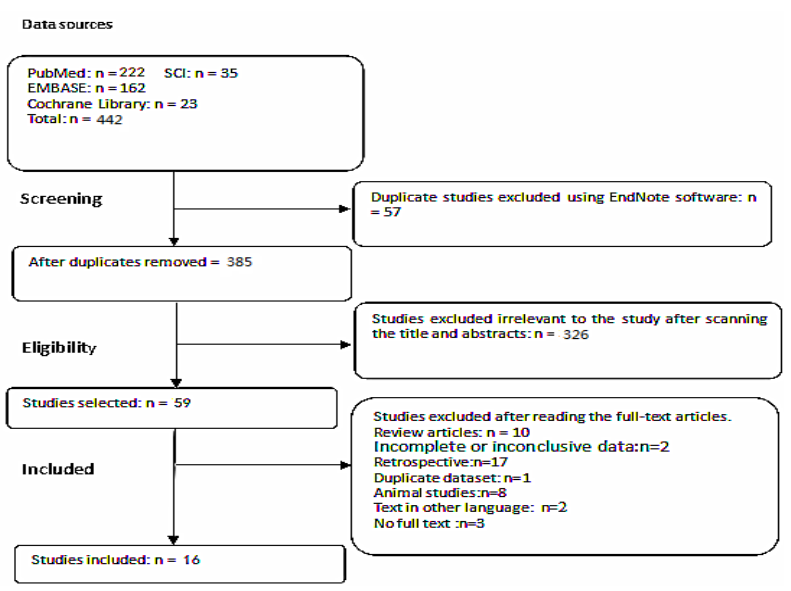

Figure 1. The Flow Chart of Literature Screening

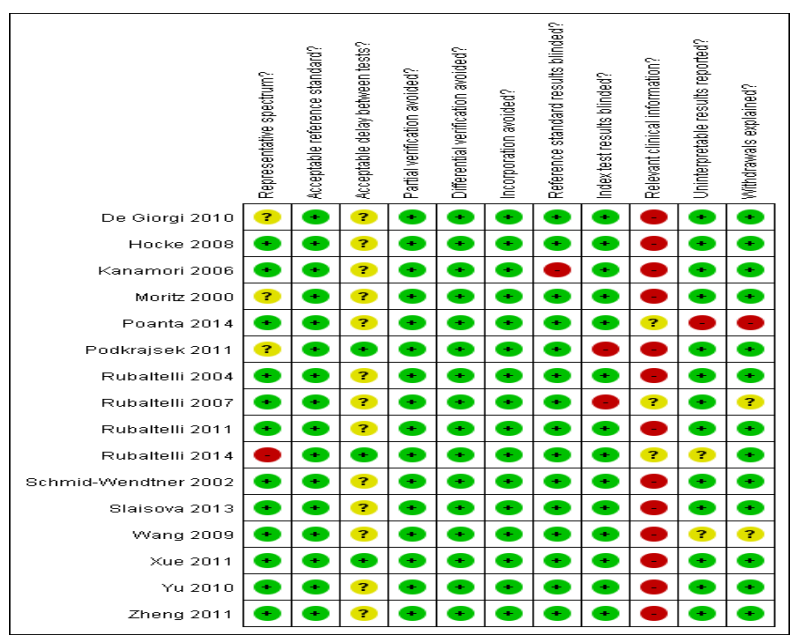

Figure 2. Assessment of Methodological Quality. Methodological quality was assessed according to the revised tool for QUADAS-2. +, yes; -, no; ?, unclear patients and 1563 lesions (584 malignant, 979 benign) in our meta-analysis. Among the 16 included studies, 15 used qualitative CEUS (Moritz et al., 2000; SchmidWendtner et al., 2002; Rubaltelli et al., 2004; Kanamori et al., 2006; Rubaltelli et al., 2007; Hocke et al., 2008; Wang et al., 2009; De Giorgi et al., 2010; Podkrajsek et al., 2011; Rubaltell et al., 2011; Zheng et al., 2011; Xue et al., 2011; Slaisova et al., 2013; Poanta et al., 2014; Rubaltelli et al., 2014.) and one used both qualitative and quantitative CEUS (Yu et al., 2010).

\section{Assessment of study quality}

According to the QUADAS scale, the methodological quality was rated as "not good" for all the included studies. Only one study fulfilled over 10 items (Xue et al., 2011); three studies met seven items (Rubaltelli et al., 2007; Wang et al., 2009; Poanta et al., 2014), five met eight (Moritz et al., 2000; Schmid-Wendtner et al., 2002; Kanamori et al., 2006; De Giorgi et al., 2010; Podkrajsek et al., 2011), and the remaining studies met nine. Our assessment of methodological quality is summarized in Figure 2.

Diagnostic accuracy of CEUS in the differential diagnosis of benign and malignant lymph nodes

Synthesis of general diagnostic performance: For
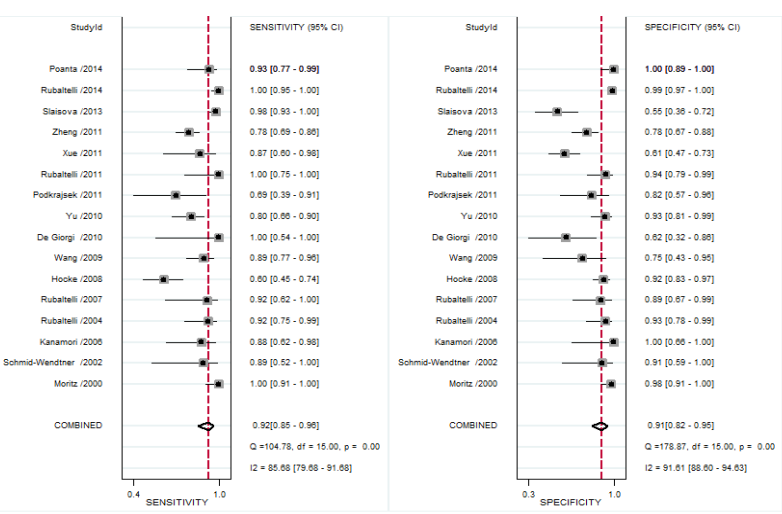

Figure 3. Forest Plots Showing the Sensitivity and Specificity of Ceus for Differentiating Between Benign and Malignant Lymph Nodes

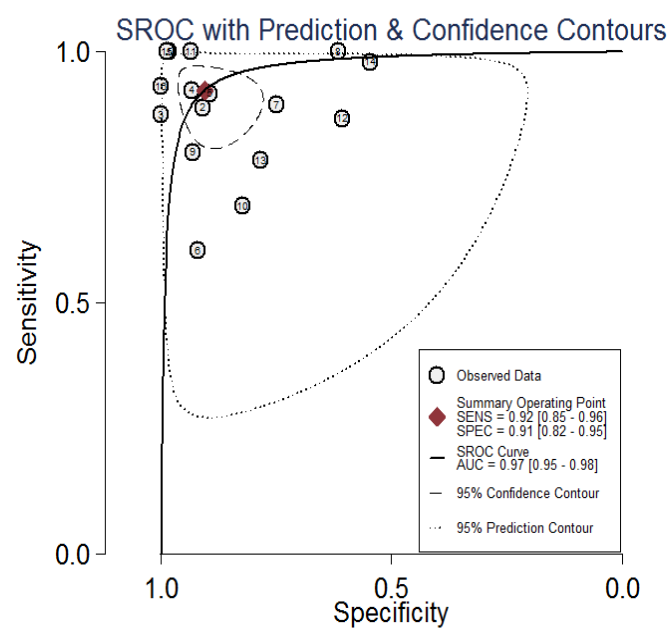

Figure 4. Summary Receiver Operating Characteristic (SROC) Curve of CEUS for the Differentiation Of Lymph Nodes 
Table 1. Main Characteristics of the Studies Included Evaluating the Performance of CEUS in the Differential Diagnosis of Benign and Malignant Lymph Nodes

\begin{tabular}{|c|c|c|c|c|c|c|c|c|c|c|c|}
\hline $\begin{array}{l}\text { Author and } \\
\text { year }\end{array}$ & $\begin{array}{l}\text { Imaging } \\
\text { modality }\end{array}$ & $\begin{array}{l}\text { Type Of } \\
\text { Scanner }\end{array}$ & $\begin{array}{c}\text { NO. } \\
\text { patients }\end{array}$ & $\begin{array}{l}\text { Mean } \\
\text { age }\end{array}$ & $\begin{array}{l}\text { Female } \\
(\%)\end{array}$ & $\begin{array}{l}\text { Con- } \\
\text { trast } \\
\text { agent }\end{array}$ & $\begin{array}{l}\text { Dose of } \\
\text { agent }\end{array}$ & $\begin{array}{l}\text { No. } \\
\text { lesions }\end{array}$ & $\begin{array}{l}\text { Histo- } \\
\text { logically } \\
\text { proven } \\
\text { malignant }\end{array}$ & $\begin{array}{l}\text { Sen } \\
(\%)\end{array}$ & $\begin{array}{l}\text { Spe } \\
(\%)\end{array}$ \\
\hline $\begin{array}{l}\text { Rubaltelli } \\
2007\end{array}$ & $\begin{array}{l}\text { CEUS/ } \\
\text { MI(0.05- } \\
0.2) / \\
\text { Qontraxt }\end{array}$ & $\begin{array}{l}\text { 7.5MHZ } \\
\text { Linear } \\
\text { transducer }\end{array}$ & 31 & $\begin{array}{l}53.6 \\
\pm 14.4\end{array}$ & 41.9 & $\begin{array}{l}\text { Sono } \\
\text { Vue }\end{array}$ & $4.8 \mathrm{ml}$ & 31 & 12 & 91.7 & 89 \\
\hline $\begin{array}{l}\text { De Giorgi } \\
2010\end{array}$ & $\begin{array}{l}\text { CEUS/ } \\
\text { MI(0.03) }\end{array}$ & $\begin{array}{l}\text { 3-9MHZ } \\
\text { Linear } \\
\text { transducer }\end{array}$ & 15 & 49 & 33.3 & $\begin{array}{l}\text { Sono } \\
\text { Vue }\end{array}$ & $2.4 \mathrm{ml}$ & 19 & 6 & 100 & 61.5 \\
\hline $\begin{array}{l}\text { Hocke } \\
2008\end{array}$ & $\begin{array}{l}\text { Contrast- } \\
\text { enhanced } \\
\text { EUS in } \\
\text { Power- } \\
\text { Doppler } \\
\text { mode }\end{array}$ & $\begin{array}{l}\text { electronic } \\
\text { linear } \\
\text { ultrasound } \\
\text { probe }\end{array}$ & 122 & $63 \pm 15$ & 24.6 & $\begin{array}{l}\text { Sono } \\
\text { Vue }\end{array}$ & $2.4 \mathrm{ml}$ & 122 & 48 & 60.4 & 91.9 \\
\hline $\begin{array}{l}\text { Kanamori } \\
2006\end{array}$ & $\begin{array}{l}\text { CE-EUS/ } \\
\text { Color Dop- } \\
\text { pler mode }\end{array}$ & 7.5MHZ & 25 & 63.7 & 32 & Levovist & $\begin{array}{l}2.5 \mathrm{~g} / \\
8 \mathrm{ml}\end{array}$ & 25 & 16 & 87.5 & 100 \\
\hline $\begin{array}{l}\text { Moritz } \\
2000\end{array}$ & $\begin{array}{l}\text { contrast- } \\
\text { enhanced } \\
\text { color } \\
\text { Doppler } \\
\text { sonography }\end{array}$ & $\begin{array}{l}\text { 12MHZ } \\
\text { Multi- } \\
\text { frequency } \\
\text { transducer }\end{array}$ & 39 & $30-81$ & 17.9 & Levovist & $\begin{array}{l}2.5 \mathrm{~g} / \\
8 \mathrm{ml} \\
4 \mathrm{~g} / \\
1 \mathrm{ml}\end{array}$ & 94 & 37 & 100 & 98.2 \\
\hline $\begin{array}{l}\text { Podkrajsek } \\
2011\end{array}$ & $\begin{array}{l}\text { CEUS/low } \\
\text { MI }\end{array}$ & $\begin{array}{l}\text { 7-12MHZ } \\
\text { Linear } \\
\text { transducer }\end{array}$ & 27 & 55 & 100 & SonoVue & $2.4 \mathrm{ml}$ & 27 & 13 & 69.2 & 82.4 \\
\hline $\begin{array}{l}\text { Rubaltelli } \\
2004\end{array}$ & $\begin{array}{l}\text { CE-HUS/ } \\
\mathrm{MI} \\
(0.05-0.2)\end{array}$ & $\begin{array}{l}7.5 \mathrm{MHZ} \\
\text { Linear } \\
\text { transducer }\end{array}$ & 45 & 51 & 37.8 & SonoVue & $4.8 \mathrm{ml}$ & 56 & 26 & 92.3 & 93.3 \\
\hline $\begin{array}{l}\text { Rubaltelli } \\
2011\end{array}$ & $\begin{array}{l}\text { CEUS/MI } \\
(0.05-0.2)\end{array}$ & $\begin{array}{l}7.5 \mathrm{MHZ} \\
\text { Linear } \\
\text { transducer }\end{array}$ & 44 & 54 & 47.8 & SonoVue & $4.8 \mathrm{ml}$ & 44 & 13 & 100 & 93.5 \\
\hline $\begin{array}{l}\text { Schmid- } \\
\text { Wendtner } \\
2002\end{array}$ & $\begin{array}{l}\text { Signal- } \\
\text { enhanced } \\
\text { Color- } \\
\text { Doppler } \\
\text { Sonography }\end{array}$ & $\begin{array}{l}\text { 8-10MHZ } \\
\text { Linear } \\
\text { transducer }\end{array}$ & 19 & 57 & 47.4 & Levovist & $\begin{array}{l}2.5 \mathrm{~g} / \\
8 \mathrm{ml}\end{array}$ & 20 & 9 & 88.9 & 90.9 \\
\hline Wang 2009 & $\begin{array}{l}\text { DCUS/MI } \\
(0.18-0.35)\end{array}$ & $\begin{array}{l}2-5 \mathrm{MHZ} \\
4 \mathrm{~V} 1 \\
\text { vector } \\
\text { transducer }\end{array}$ & 62 & $\begin{array}{l}50.0 \\
\pm 11.4\end{array}$ & 38.7 & SonoVue & $2.4 \mathrm{ml}$ & 59 & 47 & 89.4 & 75 \\
\hline $\begin{array}{l}\text { Slaisova } \\
2013\end{array}$ & $\begin{array}{l}\text { CEUS/MI } \\
(0.04)\end{array}$ & $\begin{array}{l}\text { 3-9MHZ } \\
\text { Linear } \\
\text { probe }\end{array}$ & 133 & 51 & 45.1 & SonoVue & $1.5 \mathrm{ml}$ & 133 & 100 & 98 & 54.5 \\
\hline $\begin{array}{l}\text { Xue } \\
2011\end{array}$ & $\begin{array}{l}\text { DCUS/ } \\
\operatorname{MI}(0.2)\end{array}$ & $1.5 \mathrm{MHZ}$ & 76 & 58.3 & 36.8 & SonoVue & $2.4 \mathrm{ml}$ & 76 & 15 & 86.7 & 60.7 \\
\hline $\begin{array}{l}\text { Zheng } \\
2011\end{array}$ & $\begin{array}{l}\text { DCUS/ } \\
\text { low MI }\end{array}$ & $\begin{array}{l}1-4 \mathrm{MHZ} \\
4 \mathrm{~V} 1 \\
\text { vector } \\
\text { transducer }\end{array}$ & 162 & 58.3 & 21.6 & Sonovue & $2.4 \mathrm{ml}$ & 162 & 97 & 78.4 & 78.5 \\
\hline $\begin{array}{l}\text { Rubaltelli } \\
2014\end{array}$ & CEUS & $\begin{array}{l}3.5- \\
14 \mathrm{MHZ}\end{array}$ & 540 & 53.7 & $\mathrm{NC}$ & SonoVue & $4.8 \mathrm{ml}$ & 540 & 66 & 100 & 98.7 \\
\hline $\begin{array}{l}\text { Poanta } \\
2014\end{array}$ & $\begin{array}{l}\text { CEUS/ } \\
\text { MI(0.07) }\end{array}$ & $\begin{array}{l}\text { 3-9MHz } \\
\text { linear } \\
\text { probe }\end{array}$ & 61 & 51.2 & 54.1 & SonoVue & $2.4 \mathrm{ml}$ & 61 & 29 & 93.1 & 100 \\
\hline $\begin{array}{l}\mathrm{Yu} \\
2010\end{array}$ & $\begin{array}{l}\text { CEUS/MI } \\
(0.06)\end{array}$ & $\begin{array}{l}\text { 3-9MHZ } \\
\text { Linear } \\
\text { array } \\
\text { probe }\end{array}$ & 94 & 46 & 48.9 & SonoVue & $2.4 \mathrm{ml}$ & 94 & 50 & 80 & 93.2 \\
\hline
\end{tabular}

*Sen: sensitivity; Spe: specificity; DCUS: double contrast-enhanced ultrasonography, an oral ultrasonic contrast agent combined with an intravenous contrast agent; CE-HUS: contrast-enhanced harmonic ultrasonography; CE-EUS: contrast-enhanced endoscopic ultrasonography 
Contrast-Enhanced US in Differential Diagnosis of Enlarged Lymph Nodes: A Meta-Analysis of Accuracy

Table 2. Summary Estimates for Each Subgroup

\begin{tabular}{|c|c|c|c|c|}
\hline Subgroups & Mean sensitivity & Mean specificity & Positive Likelihood Ratio & Negative Likelihood Ratio \\
\hline \multicolumn{5}{|c|}{ With Primary Tumor $(\mathrm{n}=9)$} \\
\hline & 0.89(95\%CI 0.77-0.95) & 0.92(95\%CI 0.80-0.97) & 10.7(95\%CI 4.3-26.6) & $0.12(95 \%$ CI $0.05-0.26)$ \\
\hline \multicolumn{5}{|c|}{ Without Primary Tumor $(\mathrm{n}=7)$} \\
\hline & 0.94 (95\%CI 0.80-0.98) & $0.89(95 \%$ CI $0.75-0.95)$ & 8.3(95\%CI 3.4-20.3) & $0.07(95 \%$ CI $0.02-0.27)$ \\
\hline \multicolumn{5}{|c|}{ Color and Power Doppler mode $(n=4)$} \\
\hline & 0.91(95\%CI 0.61-0.98) & 0.96(95\%CI 0.89-0.99) & 21.7(95\%CI 7.1-66.5) & $0.1(95 \%$ CI $0.02-0.51)$ \\
\hline \multicolumn{5}{|c|}{ Low MI with SonoVue $(n=12)$} \\
\hline & $0.93(95 \%$ CI $0.85-0.96)$ & $0.88(95 \%$ CI $0.77-0.94)$ & 7.7(95\%CI 3.7-16.1) & $0.08(95 \%$ CI $0.04-0.18)$ \\
\hline
\end{tabular}

*Sono Vue: the type of contrast agent; MI: Mechanical Index

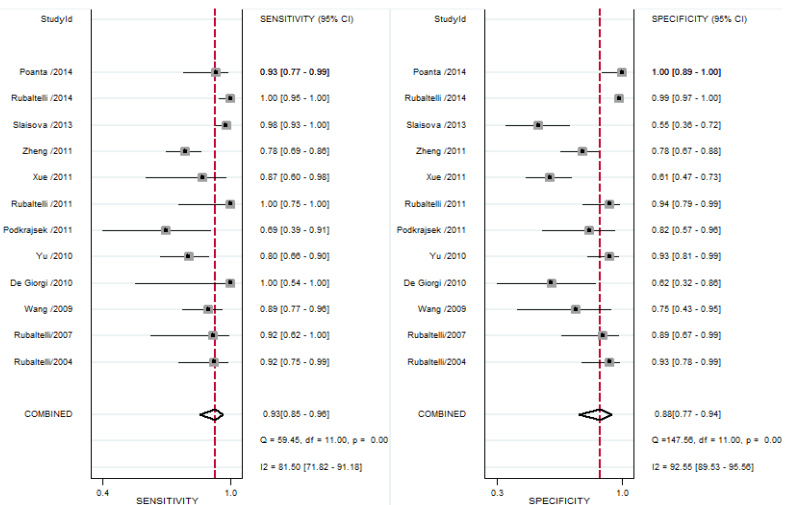

Figure 5. Forest Plots Showing the Sensitivity and Specificity of CEUS Used With Low Mi and Sonovue for the Differentiating Between Benign and Malignant Lymph Nodes

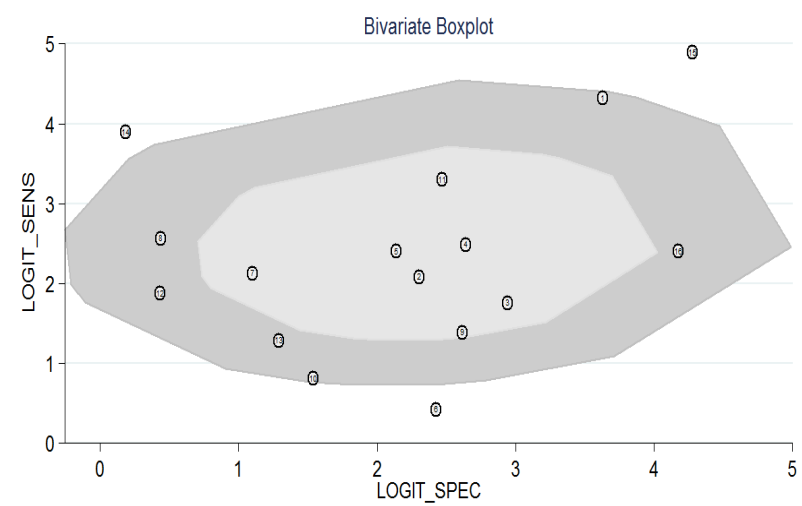

Figure 6. The Bivariate Box Plot for Evaluating the Outliers

the differential diagnosis of benign and malignant lymph nodes by CEUS, the $\mathrm{I}^{2}$ values for sensitivity and specificity were $85.68 \%$ (95\% CI, 79.68-91.68), $91.61 \%$ $(95 \%$ CI,88.6-94.63) $(p=0.000)$. The summary sensitivity and specificity were 0.92 (95\% CI, $0.85-0.96)$ and 0.91 (95\% CI, 0.82-0.95), respectively (Figure 3 ). The summary DOR was $115(95 \% \mathrm{CI}, 36-365)$ and the area under the summary receiver operating characteristics curve (AUROC) was 0.97 (95\%CI, 0.95-0.98) (Figure 4). The positive and negative LRs were 9.8 (95\%CI, 5.0-19.1) and 0.08 (95\% CI, 0.04-0.17), respectively.

Synthesis of diagnostic performance into subgroups: Seven studies (Rubaltelli et al., 2004; Kanamori et al., 2006; Rubaltelli et al., 2007; Hocke et al., 2008; Yu et al., 2010; Slaisova et al., 2013; Poanta et al., 2014;) included patients with enlarged lymph nodes only, while the other nine studies (Moritz et al., 2000; Schmid-Wendtner et al.,
Table 3. Sensitivity Analysis

\begin{tabular}{lcc}
\hline & \multicolumn{2}{c}{ Outlier exclusion } \\
\cline { 2 - 3 } Pooled results & Pooled value & $95 \%$ CI \\
\hline Sensitivity & 0.9 & $0.82-0.94$ \\
Specificity & 0.9 & $0.82-0.95$ \\
PLR & 9.4 & $4.7-18.8$ \\
NLR & 0.12 & $0.06-0.21$ \\
AUROC & 0.95 & $0.93-0.97$ \\
DOR & 81 & $0.26-260$ \\
\hline
\end{tabular}

*DOR, diagnostic odds ratio; AUROC, area under the summary receiver operating characteristics curves; NLR, negative likelihood ratio; PLR, positive likelihood ratio

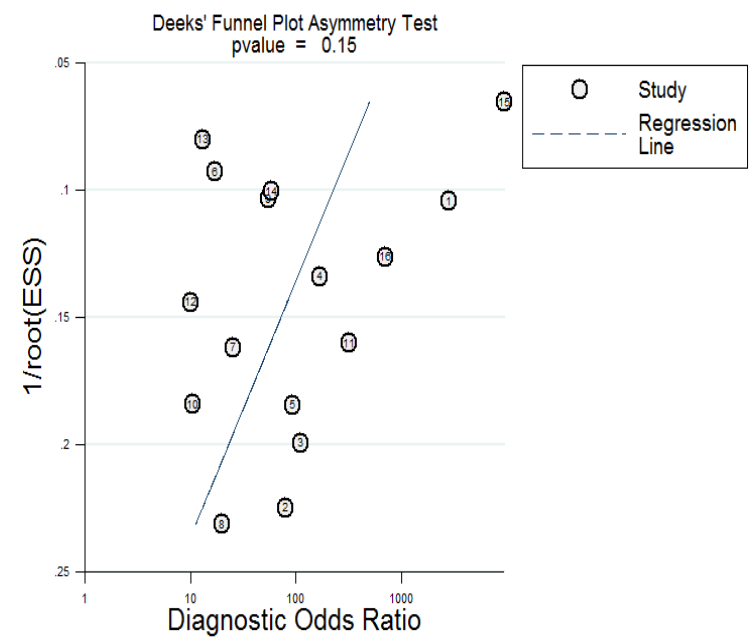

Figure 7. The Deeks' Funnel Plot Asymmetry Test For Evaluating Publication Bias among the Included Studies

2002; Wang et al., 2009; De Giorgi et al., 2010; Podkrajsek et al., 2011; Rubaltell et al., 2011; Xue et al., 2011; Zheng et al., 2011; Rubaltelli et al., 2014) included patients with enlarged lymph nodes and primary tumors.

Three studies used Color Doppler assessment (Moritz et al., 2000; Schmid-Wendtner et al., 2002; Kanamori et al., 2006), one used Power Doppler mode (Hocke et al., 2008) and the remaining studies used low mechanical index with SonoVue.

The pooled estimates for sensitivity, specificity, PLR and NLR in the subgroups were presented in Table 2.

Sensitivity analysis of the factors influencing the diagnostic performance of CEUS

According to the subgroups analysis, we excluded the studies of power and color Doppler modes that were used with Levovist and evaluated the diagnostic accuracy of CEUS using low MI and SonoVue (Figure 5). 
A bivariate boxplot (Figure 6) showed that three studies (Moritz et al., 2000; Hocke et al., 2008; Slaisova et al., 2013) were heterogeneous with respect to the other studies. After omitting the three studies, sensitivity analysis was performed: the heterogeneity $\left(\mathrm{I}^{2}\right)$ of sensitivity decreased from $85.68 \%$ (95\%CI, 79.68-91.68) to $60.92 \%$ (95\%CI, $37.28-84.59)$ and from $91.61 \%(95 \% \mathrm{CI}, 88.6-94.63)$ to $85.21 \%$ (95\%CI, 78.24-92.19) of specificity. The results of the summary estimates were presented in Table 3 .

\section{Assessment of publication bias}

To address publication bias, a funnel plot was constructed of log DOR against the standard error of the estimate of log DOR. According to Deeks' funnel plot asymmetry test, there was no publication bias among the included studies ( $p=0.15$; Figure 7$)$.

\section{Discussion}

The prevalence of enlarged lymph nodes is quite high. In past years, B-mode and Color-Doppler sonography were usually used as a first-line procedure to differentiate benign and malignant lymph nodes. There is no single criterion or even a combination of criteria that is sensitive or specific enough to diagnose malignancy; therefore, fine-needle aspiration is currently the primary diagnostic procedure. However, it has been shown to be a costeffective method, and is limited by sampling difficulties and reliable fine-needle aspiration is dependent on the sampler's experience and the cytologist's expertise (Fatima et al., 2011).

Our meta-analysis has investigated the diagnostic performance of CEUS in differentiating between benign and malignant lymph nodes. Analysis of 1563 lesions demonstrated consistently high pooled sensitivity, specificity, positive LR and DOR, but it also showed a lower negative LR. According to these results, CEUS can be used in clinical practice as an excellent diagnostic tool for diagnosis of malignant lymph nodes. This finding is of great importance because of the limitations of current approaches to identification of lymph nodes.

Subgroup analysis in this research showed that the sensitivity of CEUS seemed to be lower in patients without a primary tumor, indicating that the capability of CEUS for recognizing malignant lymph nodes in patients with a primary tumor is higher than in patients without. Furthermore, subgroup analysis revealed that the $I^{2}$ value of the subgroup with a primary tumor was much lower than that of the subgroup without a primary tumor, implying that the homogeneity of the studies included in the subgroup with a primary tumor is better. Overall, our analysis suggests that CEUS shows promise as a screening method in clinical practice for use in patients with enlarged lymph nodes, especially those with a primary tumor.

In the subgroup analysis, the sensitivity, specificity, positive likelihood ratio of the Doppler mode subgroup were higher than the subgroup of low MI. This result could be elaborated by the fewer number of studies of Doppler mode and because the methodology of CUES has changed dramatically since its introduction in the late 90s, the earlier high MI and Doppler mode used with Levovist are only of historical interest. We excluded the studies of power and color Doppler modes that were used with Levovist and evaluated the diagnostic accuracy of CEUS using low MI and SonoVue, the sensitivity and specificity are $90 \%$ and $81 \%$, respectively and this result may reveal the real clinical value.

The major limitation of this meta-analysis was the extent of the observed heterogeneity. We used a random effects approach to analyze the heterogeneous data, and a bivariate box plot was used to identify possible outliers. In the evaluation of the accuracy of CEUS, excluding three outliers reduced the heterogeneity without substantially changing the summary estimates. Possible reasons underlying the differences between the three outliers and the other studies include higher malignant lymph nodes rates, different doses of contrast agent, and the lymph node site.

In addition, it is plausible that part of the heterogeneity was caused by a large variation in the qualitative and quantitative criteria used for determining the stage of lymph nodes. Among the included studies, fifteen used qualitative criteria, and one used both qualitative and quantitative criteria, as follows: (1) intense homogeneous enhancement with no perfusion defects for benign lymph nodes, and intense inhomogeneous enhancement in the arterial phase with perfusion defects or hypo-enhancement for malignant lymph nodes;(2) in the color code image, vessels have a regular appearance with both venous and arterial vessels visible for benign lymph nodes, and an irregular appearance with only arterial vessels visible for malignant lymph nodes; ;3) predominantly hilar vessels for benign lymph nodes, and predominantly peripheral vessels or an absence of vessels for malignant lymph nodes;(4) differentiation between benign and malignant lymph nodes made on the basis of the rapidity of enhancement, intensity of enhancement (5) quantitative criteria: analysis of the time-intensity curve. Since more than three studies are needed for a meta-analysis using Stata, subgroup analysis could not be performed to evaluate the accuracy of quantitative CEUS and CEUS used with the Doppler mode and the contrast agent of Levovist. This may be another reason for the significant heterogeneity in our analysis. Additional sources of heterogeneity may include the sex proportion, the mean lymph node size, the primary tumor of the included patients, the choice of imaging modality, the design of the procedure, and QUADAS score. Nonetheless, the heterogeneity in this type of diagnostic study remains a concern, and to some extent it influences the certainty of the conclusions.

In conclusion, our meta-analysis showed that CEUS has the potential to be used as a valuable examination, with high sensitivity and specificity, to help characterize lymph nodes. However, the clinical value of CEUS needs further examination. Future large-scale studies, the development of the analytical software (like Stata, Metadisc and Revman), particularly with regard to the accuracy of quantitative CEUS for evaluating lymph nodes, are required to evaluate the screening improvement that has been hypothesized. 


\section{Acknowledgements}

This research is supported by the Chengdu Science and Technology Bureau Foundation of The clinical research for the prediction of breast cancer on the basis of ultrasonic imaging features.

\section{References}

Ahuja A, Ying M (2002). An overview of neck node sonography. Invest Radiol, 37, 333-42.

Deeks JJ, Macaskill P, Irwig L (2005). The performance of tests of publication bias and other sample size effects in systematic reviews of diagnostic test accuracy was assessed. J Clin Epidemiol, 58, 882-93.

Deeks JJ, Bossuyt PM, Gatsonis C (2010). Cochrane Handbook for Systematic Reviews of Diagnostic Test Accuracy Version 1.0. Cochrane Collaborat, http://srdta.cochrane.org/ handbook-dta-reviews.

De Giorgi V, Gori A, Grazzini M, et al (2010). Contrast-enhanced ultrasound: A filter role in AJCC stage I/II melanoma patients. Oncol, 79, 370-5.

Deng J, Zhang R, Pan Y, et al (2014). Comparison of the staging of regional lymph nodes using the sixth and seventh editions of the tumor-node-metastasis (TNM) classification system for the evaluation of overall survival in gastric cancer patients: Findings of a case-control analysis involving a single institution in China. Surgery, 156, 64-74.

Esen G (2006). Ultrasound of superficial lymph nodes. Eur J Radiol, 58, 345-59.

Fatima S, Arshad S, Ahmed Z, Hasan SH (2011). Spectrum of cytological findings in patients with neck lymphadenopathy-experience in a tertiary care hospital in Pakistan. APJCP, 12, 1873-5

Fayaz MS, El-Sherify MS, El-Basmy A, et al (2014). Clinicopathological features and prognosis of triple negative breast cancer in Kuwait: A comparative/perspective analysis. Rep Pract Oncol Radiother, 19, 173-81.

Gasparri ML, Bellati F, Pernice M, et al (2014). Surgical treatment of an isolated omental cervical cancer recurrence: report of a case and review of the literature. Tumori, 100, $52-4$

Higgins JP, Thompson SG (2002). Quantifying heterogeneity in a meta-analysis. Stat Med, 21, 1539-58.

Hocke M, Menges M, Topalidis T, Dietrich CF, Stallmach A (2008). Contrast-enhanced endoscopic ultrasound in discrimination between benign and malignant mediastinal and abdominal lymph nodes. J Cancer Res Clin Oncol, 134, 473-80.

Iannace C, Di Libero L, Lepore M, et al (2010). Prognostic and curative value of sentinel node in breast cancer. A 377 patients experience. Ann Ital Chir, 81, 103-13.

Kanamori A, Hirooka Y, Itoh A, et al (2006). Usefulness of contrast-enhanced endoscopic ultrasonography in the differentiation between malignant and benign lymphadenopathy. Am J Gastroenterol, 101, 45-51.

Karina C, Ali S, Pippa M, et al (2013). Validation of a technique using microbubbles and contrast enhanced ultrasound to identify and biopsy sentinel lymph nodes in pre-operative breast cancer patients. Eur J Surg Oncol, 39, 760-5.

Kawada H, Kurita N, Nakamura F, et al (2014). Incorporation of apical lymph node status into the seventh edition of the TNM classification improves prediction of prognosis in stage III colonic cancer. Br J Surg, 101, 1143-52.

Lijmer JG, Bossuyt PM, Heisterkamp SH (2002). Exploring sources of heterogeneity in systematic reviews of diagnostic tests. Stat Med, 21,1525-37.

Moritz JD, Ludwig A, Oestmann JW (2000). Contrast-enhanced color Doppler sonography for evaluation of enlarged cervical lymph nodes in head and neck tumors. Am J Roentgenol, 174, 1279-84.

Podkrajsek M,Hocevar M (2011). The role of contrast enhanced axillary ultrasonography in early breast cancer patients. CollAntropol, 35, 33-7.

Poanta L, Serban O, Pascu I, et al (2014). The place of CEUS in distinguishing benign from malignant cervical lymph nodes: a prospective study. Medical Ultrasonography, 16, 7-14.

Rubaltelli L, Khadivi Y, Tregnaghi A, et al (2004). Evaluation of lymph node perfusion using continuous mode harmonic ultrasonography with a second-generation contrast agent. $J$ Ultrasound Med, 23, 829-36.

Reitsma JB, Glas AS, Rutjes AW, et al (2005). Bivariate analysis of sensitivity and specificity produces informative summary measures in diagnostic reviews. J Clin Epidemiol, 58, 982-90.

Rubaltelli L, Corradin S, Dorigo A, et al (2007). Automated quantitative evaluation of lymph node perfusion on contrastenhanced sonography. Am J Roentgenol, 188, 977-83.

Rubaltelli L, Beltrame V, Tregnaghi A, et al (2011). Contrastenhanced ultrasound for characterizing lymph nodes with focal cortical thickening in patients with cutaneous melanoma. Am J Roentgenol, 196, 8-12.

Riegger C, Koeninger A, Hartung V, et al (2012). Comparison of the diagnostic value of FDG-PET/CT and axillary ultrasound for the detection of lymph node metastases in breast cancer patients. Acta Radiol, 53, 1092-8.

Rubaltelli L, Beltrame V, Scagliori E, et al (2014). Potential use of contrast-enhanced ultrasound (CEUS) in the detection of metastatic superficial lymph nodes in melanoma patients. Ultraschall in der Medizin, 35, 67-71.

Schmid-Wendtner MH, Partscht K, Korting HC, Volkenandt M (2002). Improved differentiation of benign and malignant lymphadenopathy in patients with cutaneous melanoma by contrast-enhanced color Doppler sonography. Arch Dermatol, 138, 491-7.

Schröder RJ, Rost B, Hidajat N, et al (2002). Value of contrastenhanced ultrasound vs. CT and MRI in palpable enlarged lymph nodes of the head and neck. Ro Fo, 174, 1099-106.

Stramare R, Tregnaghi A, Fitta C, et al (2004). High-sensitivity power Doppler of normal superficial lymph nodes. J Clin Ultrasound, 32, 273-6.

Smidt N, Deeks J, Moore T (2008). Guide to the contents of a Cochrane review and protocol for Diagnostic Test Accuracy version 1.0.1. Cochrane Collaborat. http://www.cochrane. org/resources/handbook.

Steppan I, Reimer D, Muller-Holzner E, et al (2010). Breast cancer in women: evaluation of benign and malignant axillary lymph nodes with contrast-enhanced ultrasound. Ultraschall Med, 31, 63-7.

Sun DS, Chen Y, Zhong JY, Hu ZM, Hu HY (2012). Application of CEUS-guided needle biopsy for superficial lymphadenopathy.. CJIIT, 9, 229-32 (in Chinese).

Slaisova R, Benda K, Jarkovsky J, et al (2013). Contrastenhanced ultrasonography compared to gray-scale and power doppler in the diagnosis of peripheral lymphadenopathy. EurJ Radiol, 82, 693-8.

Wang CL, Yang YM, Cui J, et al (2009). Diagnostic value of double contrast-enhanced ultrasonography in preoperative staging of gastric cancer. Zhonghua Zhong Liu Za Zhi, 31, 701-4.

Whiting PF, Rutjes AW, Westwood ME, et al (2011). QUADAS-2: a revised tool for the quality assessment of diagnostic accuracy studies. Ann Intern Med, 155, 529-36. 
Ya Jin et al

Xue N, Huang P, Aronow WS, et al (2011). Predicting lymph node status in patients with early gastric carcinoma using double contrast-enhanced ultrasonography. Arch Med Sci, 7, 457-64.

Yu M, Liu Q, Song HP, et al (2010). Clinical application of contrast-enhanced ultrasonography in diagnosis of superficial lymphadenopathy. J Ultrasound Med, 29, 735-40.

Zheng Z, Yu Y, Lu M, et al (2011). Double contrast-enhanced ultrasonography for the preoperative evaluation of gastric cancer: a comparison to endoscopic ultrasonography with respect to histopathology. Am J Surg, 202, 605-11. 